\title{
Fuzzy modeling of the road traffic hazard level
}

\author{
Elena Pechatnova $^{1 *}$, Vasily Kuznetsov ${ }^{2}$, and Kirill Safronov ${ }^{1}$ \\ ${ }^{1}$ Altai State University, 656049 Barnaul, Lenina ave, 61, Russia \\ ${ }^{2}$ Altai State Agricultural University, 656049 Barnaul, Krasnoarmeysky ave., 98, Russia \\ ${ }^{3}$ Siberian State Automobile and Highway University, 644080, Omsk, Mira ave., 5, Russia
}

\begin{abstract}
The article is devoted to the author's concept development of the short-term road safety management on the federal roads in Russia. The results of development the rule for calculating hazard level depending on the road accidents risk are presented. The mathematical basis of the research is fuzzy modeling. The main stages of modeling are performed using the FisPro software. The concept of acceptable risk has been implemented based on the target values of state programs to improve traffic safety. The developed rule base is the basis for determining the hazard level, which can be the basis for calculating the main parameter of short-term road safety management - the hazard level.
\end{abstract}

\section{Introduction}

The road transport development, its production, economic and socio-cultural role increase sets the task of road safety improvement. Road accidents are one of the world's problems [1]. At present, the accident reduction is the important governmental direction in many countries.

Various programs and strategies are being adopted to deal with accidents. Many states with high level of traffic safety realize the "Vision Zero" policy or similar ones.

Accident rates in Russia are higher than in many developed countries [2]. The directions for accident reduction are fixed in the Road safety strategy in the Russian Federation for 2018-2024. Its goal is to reduce social risk and aim for zero deaths by 2030 . The Strategy fixes the main directions for road safety increase. One of the main is the improvement of the road safety management system.

Lots of researches are devoted to road safety management. In particular, the research [3] contains the results of development the road safety management system in Poland. It bases on the road risk management model. The research work [4] describes the methods and processes of the road traffic risk management, which can improve traffic safety. Research [5] summarizes and systematizes scientific approaches to the road safety improvement. Efficiency and effectiveness assessment of the road safety management system in Malaysia and ways to improve it are considered in this research [6]

The large number of studies shows the high potential of the evidence-based approaches to road safety management. However, developments in this area should be related to the state and law features of the country or region. Therefore, scientific results adapted to

* Corresponding author: phukcia@yandex.ru 
Russian conditions are needed for improvement the road safety management system in Russia. In addition, the significant lack of researches in the field of short-term road safety management is revealed. It implies the urgent response to the road accident risk increase.

The road accident risk is the characteristic of the control object in the short-term road safety management system. It is assessed in real-time. According to the concept of acceptable risk, scaling the risk by the level of acceptability is necessary for making decisions. The acceptability level can be denoted as the "road traffic hazard level" in the area of road safety. The important scientific problem and the goal of the research work is development the rule for calculating the hazard level depending on the road accident risk.

\section{Methods and Materials}

The federal roads are characterized by the highest severity of road accidents in Russia. Previously published authors' works present the model for assessing road accident risk in the space-time cell $i \times t$, where $i$ - is road section (generally kilometer section), $\mathrm{t}-$ is the time at which the risk is calculated [7]. The model makes it possible to assess the road accident risk in the short time interval according to the formula (1):

$$
R^{i \times t}=R_{\text {road }}^{i} \cdot R_{e}^{t}
$$

where $R^{i \times t}-$ is the risk of road traffic accident in the space-time cell $i \times t$,

$R_{\text {road }}^{i}$ - risk on the $i$ - th section of the road due to the constant characteristics of the road,

$R_{e}^{t}-$ risk in the $t$-th time, due to the influence of the external environment (meteorological parameters, traffic intensity, road works, etc.).

Checking the model adequacy shows that it can be used to assess the road accidents risk in real-time on the federal roads of Russia.

The definition of the rule for calculating the hazard level depending on the road accident risk is carried out on the basis of the fuzzy set theory and fuzzy inference algorithm.

Fuzzy modeling is used in the development of control models. Its application allows one to obtain more accurate results than when using traditional analytical models, since it allows the most adequate reflection of the uncertainty aspects of the real environment [8]. Fuzzy modeling is widely represented in road safety studies, in particular in $[9,10]$.

Fuzzy modeling is used in the control models development. Its application allows obtaining more accurate results in comparison with the use of traditional analytical models, because it adequately reflects the uncertainty aspects of the real environment [8]. Fuzzy modeling is widely represented in road safety studies, for example, in $[9,10]$.

Fuzzy modeling is performed with the use of FisPro software. The level of acceptable risk is determined on the basis of the state program to improve road safety in the Altai Territory.

\section{Results and Discussion}

An input linguistic variable is set: the name is "road accident risk", its set of terms is "low, high, extremely high", the scope is $(0, \infty)$. The triangular and trapezoidal shapes for the membership functions are selected. The following calculations are made for determination the term-sets boundaries. The target value for the number of deaths for 2021 is found on the basis of the regional state program of the Altai Territory in the field of road safety improvement. This value is 230 deaths per year, which is 0.92 per 1 kilometer of the federal road per year. This value is the maximum acceptable risk. To determine the centers of other 
term-sets, it should be assumed that the center of the term-set "high" is the doubled value of the acceptable risk, and the center of the term-set "extremely high" is the triple value. The boundaries are set within $30 \%$. The fuzzy membership function of the input variable is shown in the Figure 1.

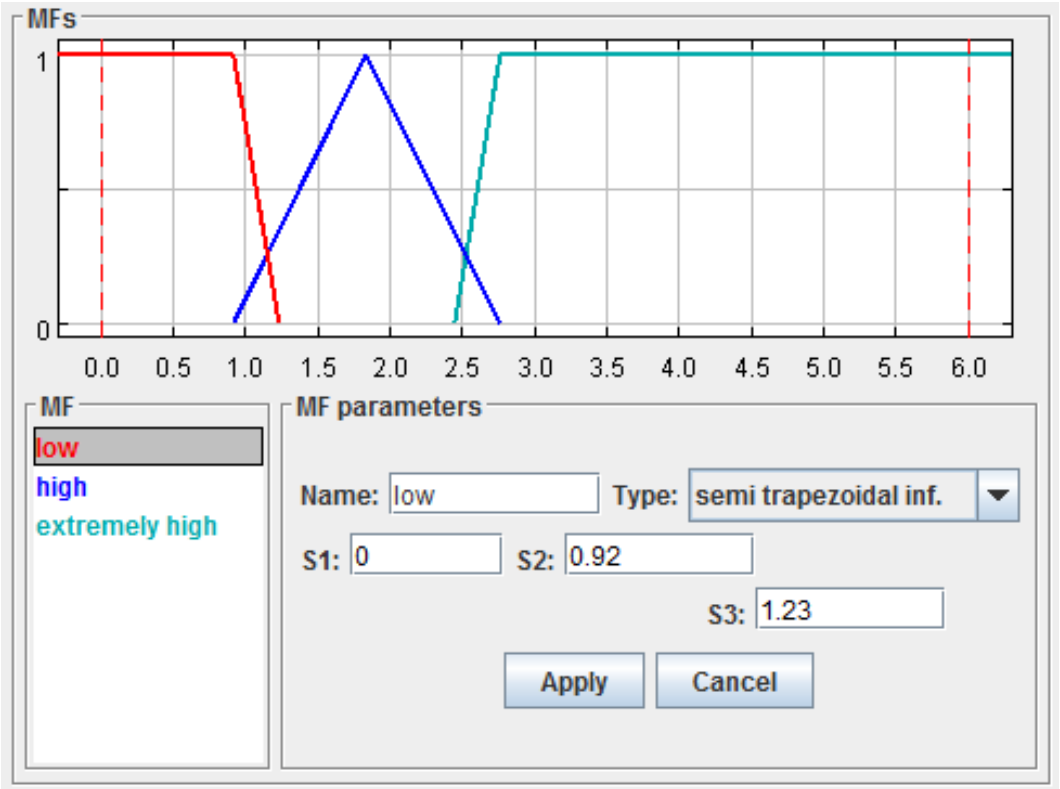

Fig. 1. The Membership Function of the Input Variable (Road Accident Risk, or Risk of RTA)

An output linguistic variable is set: the name is "hazard level", its set of terms is "low, high, extremely high", the scope is $(0, \infty)$. It is assumed that the center of the term-set "low" is the interval $(0 ; 1]$, the kernel of the term-set "high" is $(2)$, the kernel of the termset "extremely high" is (3). The membership functions of the input variable are shown in the Figure 2.

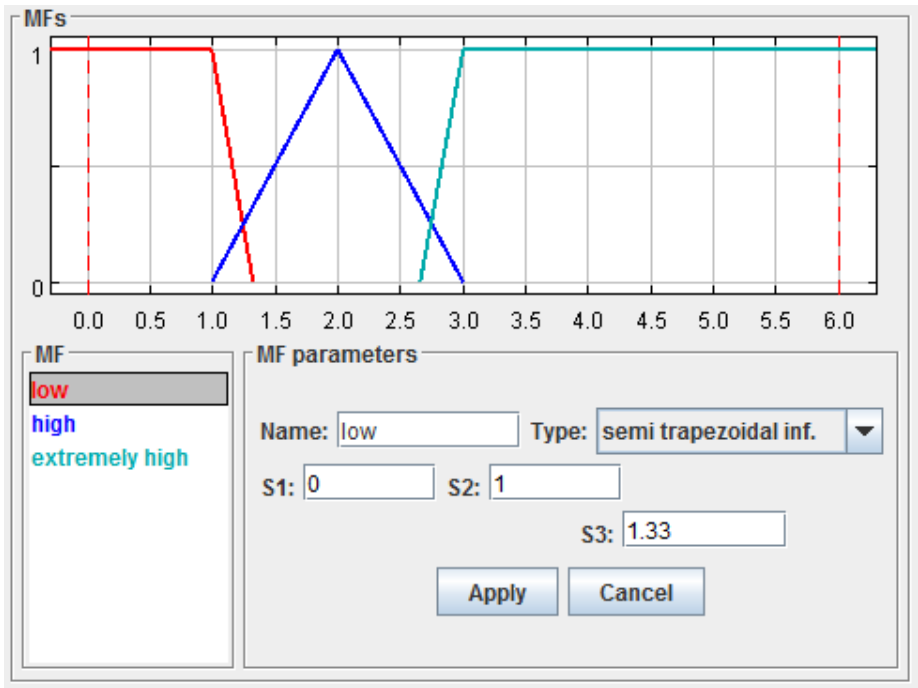

Fig. 2. The Membership Function of the Output Variable (Hazard Level) 
The rule base is formulated (1). Its implementation in the FisPro program is shown in the Figure 3.

\begin{tabular}{|r|c|c||c|}
\hline Rule & Active & IF Risk of RTA & THEN Hazard level \\
\hline 1 & $\boldsymbol{V}$ & low & low \\
\hline 2 & $\boldsymbol{V}$ & high & high \\
\hline 3 & $\boldsymbol{V}$ & extremely high & extremely high \\
\hline \multicolumn{2}{|r}{} \\
\hline
\end{tabular}

Fig. 3. The Rule Base

$$
\begin{aligned}
& \text { Rule_1: IF "Risk of RTA" is "low" THEN "Hazard level" is "low" } \\
& \text { Rule_2: IF "Risk of RTA" is "high" THEN "Hazard level” is "high" } \\
& \text { Rule_3: IF "Risk of RTA" is "extremely high" } \\
& \text { THEN "Hazard level" is "extremely high" }
\end{aligned}
$$

The next stages of modeling (fuzzification, aggregation, accumulation, defuzzification) are performed with the use of specified software application. The example of the fuzzy inference implementation is shown in the Figure 4.

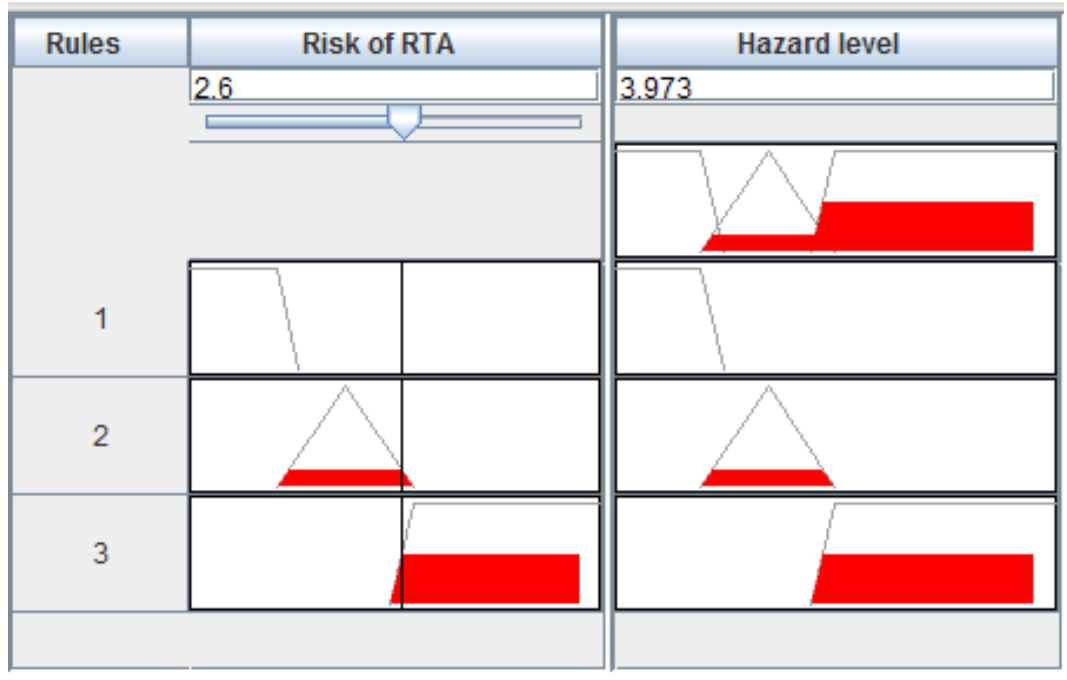

Fig. 4. Fuzzy Inference

Entering the value of road accident risk allows determining the hazard level that can be used in the short-term management system. To obtain the similar model in other regions, it is necessary to correct the term-sets centers of the input variable according to the described method.

\section{Conclusion}

The rule base for calculating the hazard level depending on the road accident risk is obtained with the use of fuzzy modeling. The presented method for determination the term- 
sets of the input and output variable realizes the concept of acceptable risk based on the target indicators of government programs. The term-sets centers of the input variable must be adjusted annually. It is recommended to use the hazard level value as the main parameter of the short-term management system.

\section{References}

1. A.S. Afanasyev, S.A. Evtyukov, N.V. Chudakov, J. Phys.: Conf. Ser., 1399, 055019 (2019)

2. M.G. Simul, S.M. Porkhacheva, IOP Conf. Ser.: Mater. Sci. Eng., 786, 012050 (2020).

3. A. Szymanek, Communications - Scientific letters of the University of Zilina, 23, F1F10 (2020)

4. A. Nicholson, ASCE-ASME Journal of Risk and Uncertainty in Engineering Systems, Part A: Civil Engineering, 6(1), 04019017 (2020)

5. H. Safarpour, D. Khorasani-Zavareh, R. Mohammadi, Chinese Journal of Traumatology, 23 (2), pp. 113-121 (2020)

6. Z. Eusofe, H. Evdorides, IATSS Research, 41(4), pp. 172-181 (2017)

7. E. Pechatnova, V. Kuznetsov Advances in Intelligent Systems and Computing AISC, 1258, pp. 136-145 (2021)

8. L.E. Kushchenko, I.A. Novikov, A.N. Novikov, Bulletin of Civil Engineers, 5 (64), pp. 157-162 (2017)

9. E. Alemneh, S.-M. Senouci, M.-A. Messous, Pervasive and Mobile Computing, 69, 101285 (2020)

10. F. Riaz, S. Khadim, R. Rauf, M. Ahmad, S. Jabbar, J. Chaudhry, Computer Networks, 143, pp. 62-73 (2018) 